\title{
Durability properties of inorganic polymer concrete using fly ash and slag
}

\author{
J.R. Mackechnie \& A.C.N. Scott \\ Department of Civil and Natural Resources Engineering, University of Canterbury, New Zealand
}

\begin{abstract}
The potential durability of inorganic polymer concrete made with fly ash and slag was investigated by comparing the durability properties of a range of inorganic polymer and Portland cementbased concrete. Concrete was cured at ambient and elevated temperatures to simulate normal site and precast concrete conditions. Findings from porosity, oxygen permeability and chloride resistance testing show that inorganic polymer concrete has significant differences in microstructure to Portland cement concrete. The higher porosity of inorganic polymer concrete was found to be caused by differences in paste porosity and the presence of compaction voids due to the viscous nature of the material. High strength IPC mixes had moderate permeability but lower strength IPC mix had poor resistance to permeation. Chloride resistance of IPC was not consistent and was generally much poorer than PC-based concrete. Durability properties of inorganic polymer concrete were found to vary considerably depending on mix design and initial curing and did not always follow predictable trends found with PC-based concrete.
\end{abstract}

\section{INTRODUCTION}

Inorganic polymer concrete (IPC) is made using waste materials such as fly ash and ground granulated blast-furnace slag and usually does not contain Portland cement (PC). These binders are less reactive than Portland cement, containing less calcium and more silica and alumina. To improve the reactivity of these binders, an alkali or alkalisilicate activating solution is used and thermal curing is sometimes required. The activating solution dissolves silicates and aluminates, which undergo condensation reactions to produce increasingly higher molecular weight species. This leads to the formation of an alkali aluminosilicate gel that is primarily amorphous but may also contain crystalline zeolites (Roy, et al., 1992).

IPC has several advantages including economic savings by using waste materials, environmental benefits due to reductions in embedded energy and carbon dioxide and technical benefits such as high strength and fire resistance (Phair 2006). The microstructure of IPC is complex, differs from PCbased concrete and is only starting to be understood by researchers. It is known that the bonding is strong but the material can be porous with significant amounts of unreacted binder (Duxson, et al., 2007). Given the unique microstructure of the material, careful characterisation is required to predict the durability performance, especially as it is started to be commercially produced in Australia.
Porosity of IPC differs from PC concrete in that capillary porosity is largely absent and instead there are large, isolated pores left by dissolved binder material and connected together by smaller gel pores (Lloyd, et al., 2009). While IPC gel pores are larger than those found in PC gel, the overall microstructure is thought to be less open and connected compared with PC concrete. This would suggest that increased porosity of IPC would not necessarily make the material less resistant to mass transfer and therefore less durable overall.

The objective of this study was to assess the likely durability performance of a range of IPC and PC-based concrete mixes that could be used in structural and precast concrete. Initial curing was either at ambient temperature typical for structural concrete or thermal curing, which is often applied to precast concrete to allow rapid demoulding.

\section{EXPERIMENTAL STUDY}

\subsection{Materials}

Details of the chemical composition of cementitious and pozzolanic binders used in this investigation are shown in Table 1. A wide range of binders was trialled to assess the broader applicability of IPC technology to construction. Coarse aggregate used in concrete mixes was $13 \mathrm{~mm}$ crushed greywacke sandstone while fine aggregate was 
Table 1. Chemical composition of binders.

\begin{tabular}{lcrrrrr}
\hline $\begin{array}{l}\text { Oxide } \\
(\text { wt } \%)\end{array}$ & PC & HFA & GFA & LFA & PSL & SSL \\
\hline $\mathrm{Na}_{2} \mathrm{O}$ & 0.19 & 0.70 & 0.24 & 0.33 & 0.16 & 0.18 \\
$\mathrm{MgO}$ & 1.00 & 2.67 & 1.47 & 1.19 & 6.16 & 12.99 \\
$\mathrm{Al}_{2} \mathrm{O}_{3}$ & 4.10 & 21.06 & 31.06 & 31.54 & 13.99 & 15.80 \\
$\mathrm{SiO}_{2}$ & 22.85 & 47.87 & 47.20 & 54.74 & 33.22 & 32.58 \\
$\mathrm{P}_{2} \mathrm{O}_{5}$ & 0.10 & 0.43 & 0.69 & 0.57 & 0.02 & 0.01 \\
$\mathrm{SO}_{3}$ & 2.30 & - & - & - & 2.77 & - \\
$\mathrm{K}_{2} \mathrm{O}$ & 0.50 & 0.51 & 0.51 & 0.85 & 0.43 & 0.54 \\
$\mathrm{CaO}^{2}$ & 66.5 & 12.75 & 2.97 & 4.38 & 41.87 & 35.42 \\
$\mathrm{TiO}_{2}$ & 0.20 & 1.21 & 1.74 & 1.50 & 0.55 & 0.53 \\
$\mathrm{Fe}_{2} \mathrm{O}_{3}$ & 2.40 & 10.94 & 11.17 & 3.29 & 0.34 & 1.11 \\
$\mathrm{MnO}^{2}$ & 0.20 & 0.08 & 0.16 & 0.02 & 0.24 & 0.03 \\
$\mathrm{LOI}^{2}$ & 2.10 & 0.87 & 2.79 & 0.70 & 0.26 & 2.61 \\
\hline
\end{tabular}

well-graded greywacke sand that had a fineness modulus of 2.70 .

Cementitious and pozzolanic binders used in this investigation are given below:

PC - Portland cement from Whangarei, NZ

HFA - Fly ash from Huntly power station, NZ

GFA - Fly ash from Gladstone, Australia

LFA - Fly ash from Lethabo power station, SA

PSL - Ground gran. blast-furnace slag from

Aus.

SSL—Ground granulated Corex slag from SA

\subsection{Concrete mixtures}

Concrete mixtures used for this testing programme are shown in Table 2. All concrete mixes were designed to have a nominal slump of $180 \mathrm{~mm}$ and a total binder content of $430 \mathrm{~kg} / \mathrm{m}^{3}$. The relatively high consistence of the concrete was selected due to the viscous nature of these mixes in the fresh state.

Concrete was mixed in a laboratory pan mixer for five minutes with special attention taken to avoid contamination of IPC mixes with Portland cement residues. Paste samples were also made using the same mixture proportions, being mixed by hand and were cast into $50-\mathrm{mm}$ diameter by $100-\mathrm{mm}$ high cylinder moulds. Paste was allowed to stiffen slightly before casting to prevent settlement.

No chemical admixture was used in IPC mixes since standard chemical admixtures are ineffective at the very high $\mathrm{pH}$ of the material (Criado et al., 2009). A poly-carboxylate high range water-reducing admixture was used in the PC-based concrete mixes. The activator solution for IPC was made with moderate concentrations of sodium hydroxide (wt. $30 \%$ ). A grade $\mathrm{N}$ sodium silicate solution with $\mathrm{Na}_{2} \mathrm{O}(8 \%), \mathrm{SiO}_{2}(26 \%)$ and $\mathrm{H}_{2} \mathrm{O}(66 \%)$ was also used in IPC. $\mathrm{SiO}_{2} / \mathrm{Al}_{2} \mathrm{O}_{3}$ ratios
Table 2. Concrete mix designs (kg per cubic metre).

\begin{tabular}{lrrrrrr}
\hline Material & PC & FA & SL & IPNZ & IPAS & IPSA \\
\hline PC & 430 & 300 & 215 & 0 & 0 & 0 \\
Fly ash & 0 & 130 & 0 & 215 & 323 & 323 \\
Slag & 0 & 0 & 215 & 215 & 108 & 108 \\
Water & 170 & 160 & 167 & 195 & 168 & 166 \\
Gwk sand & 850 & 850 & 850 & 800 & 800 & 800 \\
13 mm & 1000 & 1000 & 1000 & 950 & 950 & 950 \\
HRWR (ml) & 1500 & 750 & 1500 & 0 & 0 & 0 \\
\hline
\end{tabular}

were reasonably consistent for IPC at between 1.9 and 2.5 while $\mathrm{N}_{2} \mathrm{O} / \mathrm{Al}_{2} \mathrm{O}_{3}$ ratios ranged from 0.25 to 0.50 .

Mechanical vibration of cylinders was done at $2500 \mathrm{rpm}$. for 15 seconds for each of three layers to ensure uniform energy was applied during consolidation. High-temperature grease was applied to steel moulds for IPC to prevent the material adhering to the steel surface. Concrete samples were cured at either 21 or $60^{\circ} \mathrm{C}$ for 24 hours before wet curing at $21{ }^{\circ} \mathrm{C}$ until testing at 28 days. This initial curing was done in sealed steel moulds and IPC samples were sealed in plastic before curing in water to prevent dissolution of alkali solutions.

\subsection{Fresh concrete testing}

The workability of concrete was assessed to quantify how feasible IPC mixes would be for use in readymix and precast concrete applications. Fresh concrete sampling was done in accordance with NZS 3112 with test results reported based on a single test sample (NZ Standards 1986).

- slump testing in accordance with NZS 3112

- rheology testing using a BML4 coaxial viscometer

\subsection{Hardened concrete testing}

The hardened performance of concrete was assessed to ensure that the selected concrete mixes would perform adequately as a structural material. Hardened properties of concrete were assessed at 28 days with test results being the average of three samples.

- hardened density and compressive strength was done using 100-mm cylinders

- elastic modulus was measured using $150-\mathrm{mm}$ cylinders in accordance with ASTM C469 (2002)

- drying shrinkage of concrete was assessed using $75 \times 75 \times 285-\mathrm{mm}$ prisms exposed to drying at $23{ }^{\circ} \mathrm{C}$ and $50 \%$ R.H. (Australian Standards 1992) 
Durability of concrete was assessed using laboratory techniques designed to characterise mass transport properties such as permeation and diffusion (Alexander et al., 1999). These methods provide an early-age indications of microstructure that are known to affect durability performance of structural concrete. All testing of durability properties was done on triplicate cylinder samples of $100-\mathrm{mm}$ diameter and typically 25 or $50 \mathrm{~mm}$ thick:

- effective porosity was determined by vacuum saturation and oven-drying of concrete after curing in water

- oxygen permeability was measured on ovendried $\left(50{ }^{\circ} \mathrm{C}\right)$ concrete using a falling head permeameter, with results being related to the carbonation resistance of concrete

- chloride resistance was measured using the Nordic chloride migration test and ASTM bulk diffusion for a period of 90 days (Nordtest 1999, ASTM 2004)

\section{RESULTS}

\section{$3.1 \quad$ Fresh properties}

Results of fresh concrete testing are shown in Table 3 where three separate batches of each concrete mix were tested. The rheology of concrete was assessed by determining the yield shear stress (boundary between liquid and solid states) and plastic viscosity (internal resistance to flow of a liquid) of the material directly after measuring consistence.

Consistence values of concrete were all reasonably close to the target slump of $180 \mathrm{~mm}$, ranging from 150-230 mm. While all concrete had relatively high slump, the workability was found to vary quite significantly when assessed using rheology. PC-based concrete were found to have low yield shear stress and moderate plastic viscosity that was within the expected range considering the high slump and the relatively high binder content used

Table 3. Fresh concrete properties of PC \& IPC.

\begin{tabular}{llll}
\hline $\begin{array}{l}\text { Concrete } \\
\text { type }\end{array}$ & $\begin{array}{l}\text { Slump } \\
(\mathrm{mm})\end{array}$ & $\begin{array}{l}\text { Yield shear } \\
\text { stress }(\mathrm{Pa})\end{array}$ & $\begin{array}{l}\text { Plastic } \\
\text { Viscosity } \\
(\text { Pa.s })\end{array}$ \\
\hline PC & 200 & 191 & 81 \\
FA & 180 & 466 & 109 \\
SL & 180 & 478 & 91 \\
IPNZ & 220 & 162 & 88 \\
IPAS & 230 & 219 & 255 \\
IPSA & 190 & 227 & 253 \\
\hline
\end{tabular}

in the material. IPC had higher plastic viscosity values, especially mixes IPAS and IPSA that were very sticky and were difficult to compact. Yield shear stress values for IPC were quite variable but with only IPAS being higher at $950 \mathrm{~Pa}$.

The difference in rheology of IPC and PC-base concrete is shown in Figure 1 and compared with typical ranges for self-compacting concrete (SCC) and structural concrete designed for pumping (i.e., moderate consistence with slump values above $120 \mathrm{~mm}$ ). The consistently high plastic viscosity of IPAs and IPSA mixes was apparent while IPNZ had values within the normal range.

No dedicated setting test was done but visual indications suggested that IPC had noticeably shorter setting times than PC-based concrete, mostly notably IPAS and IPSA, which stiffened within 60 minutes. The composition of IPAS and IPSA mixes was significantly different from IPNZ mix having higher $\mathrm{SiO}_{2} / \mathrm{Al}_{2} \mathrm{O}_{3}$ ratios. Stiffening after initial set was rapid for IPC mixes and retempering and reworking was not possible after initial set. This rapid setting would limit the materials application to precast production.

\subsection{Structural and dimensional stability properties}

Results of hardened concrete properties tested at 28 days are shown in Table 4 . No longer-term testing of these properties was undertaken but concrete containing fly ash or slag would be expected to have significant further strength development.

The most notable feature of IPC results was that IPNZ concrete was adversely affected by thermal curing. The high calcium content in HFA produces a hybrid microstructure containing both aluminosilicates and calcium silicates that appears to respond best to ambient curing conditions. In contrast, other IPC mixes showed improvements

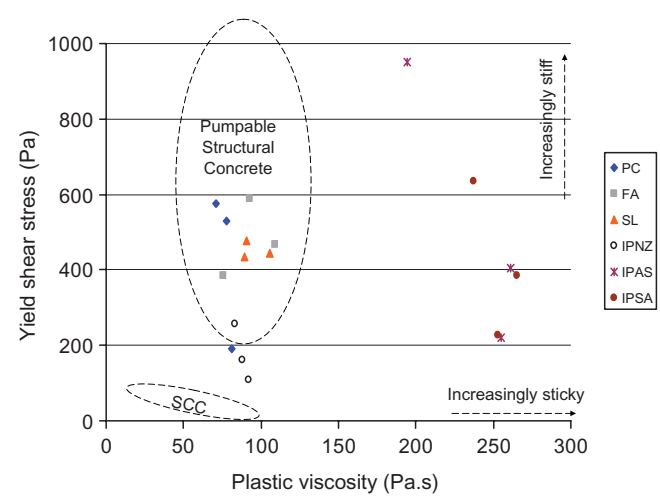

Figure 1. Rheochart showing PC and IPC mixes. 
Table 4. Structural properties measured at 28 days.

\begin{tabular}{|c|c|c|c|c|c|c|c|}
\hline Property & Temp & $\mathrm{PC}$ & FA & SL & IPNZ & IPAS & IPSA \\
\hline \multirow{2}{*}{$\begin{array}{l}\text { Hard. } \\
\text { density } \\
\qquad\left(\mathrm{kg} / \mathrm{m}^{3}\right)\end{array}$} & $21^{\circ} \mathrm{C}$ & 2471 & 2441 & 2434 & 2385 & 2413 & 2396 \\
\hline & $60^{\circ} \mathrm{C}$ & 2472 & 2415 & 2408 & 2400 & 2391 & 2396 \\
\hline \multirow{2}{*}{$\begin{array}{l}\text { Comp. } \\
\text { strength } \\
\text { (MPa) }\end{array}$} & $21^{\circ} \mathrm{C}$ & 64.5 & 69.4 & 76.6 & 45.7 & 75.8 & 82.2 \\
\hline & $60^{\circ} \mathrm{C}$ & 61.5 & 58.1 & 59.6 & 26.5 & 75.5 & 86.5 \\
\hline \multirow{2}{*}{$\begin{array}{l}\text { Elastic } \\
\text { modulus } \\
(\mathrm{GPa})\end{array}$} & $21^{\circ} \mathrm{C}$ & 39.5 & 38.5 & 40.7 & 30.3 & 31.6 & 32.3 \\
\hline & $60^{\circ} \mathrm{C}$ & 39.0 & 37.9 & 38.8 & 23.5 & 34.4 & 34.5 \\
\hline \multirow{2}{*}{$\begin{array}{l}\text { Drying } \\
\text { shrink. } \\
\text { (mstr) }\end{array}$} & $21^{\circ} \mathrm{C}$ & 584 & 565 & 624 & 539 & 1352 & 1499 \\
\hline & $60^{\circ} \mathrm{C}$ & 544 & 540 & 582 & 216 & 456 & 552 \\
\hline
\end{tabular}

in compressive strength and elastic modulus when thermally cured.

IPAS and IPSA produced higher compressive strength than any of the PC-based concretes. PCbased concrete had higher elastic moduli than IPC when ambient or thermally cured but differences were not as significant as those previously reported (Wangpo et al., 2010). Drying shrinkage was also generally higher for IPC, especially when ambient cured. IPAS and IPSA had extremely high levels of drying shrinkage when ambient cured with cracking being evident on test specimens. These materials need thermal curing to control dimensional stability much like autoclaving is used to stabilise some concrete mixes.

\subsection{Mass transport properties}

\subsubsection{Porosity}

Effective porosity measures the bulk porosity of the concrete in terms of water-filled voids but does not assess the connectivity of the pore structure. Porosity of PC-based concrete was significantly lower than concrete made with IPC, which was not consistent with trends found for porosity of the equivalent pastes. The relationship between porosity of concrete and paste is shown in Figure 2. The higher porosity of concrete made with IPAS or IPSA was due to the presence of compaction voids caused by the lower workability of these materials, which had higher plastic viscosity. Concrete made with IPC had consistently higher porosity than the equivalent paste would have predicted (typically $70 \%$ of the paste porosity).

Steam curing is typically recommended for IPC with high $\mathrm{SiO}_{2} / \mathrm{Al}_{2} \mathrm{O}_{3}$ ratios to provide a better microstructure and consequently improved durability performance (Kovalchuk 2007). Thermal curing has been shown to improve the degree of hydration and development of stable, hardened

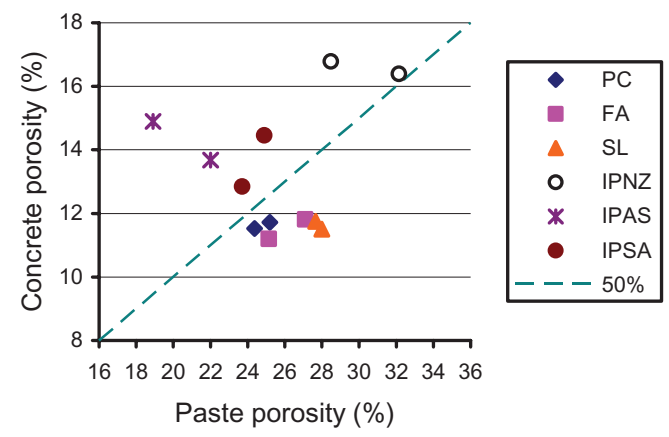

Figure 2. Concrete porosity versus paste porosity.

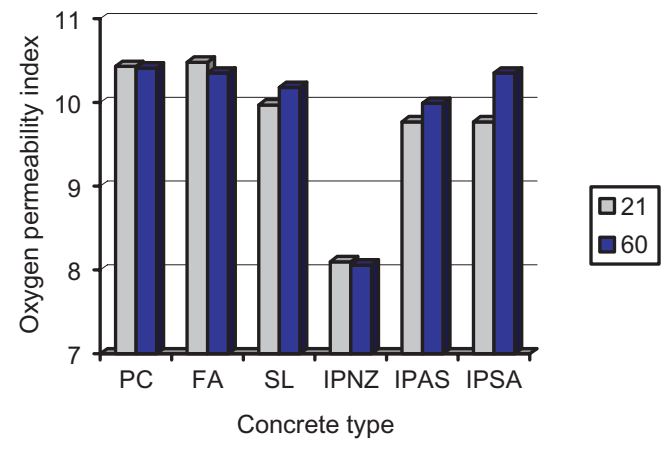

Figure 3. Oxygen permeability results at 28 days.

phases provided moisture is not lost by drying. This research found that thermal curing increased the porosity of PC-based concrete but reduced the porosity of IPC, most significantly for IPAS and IPSA which have higher silica contents than IPNZ.

\subsubsection{Oxygen permeability}

Oxygen permeability measures the Darcy coefficient of permeability of concrete to oxygen flow. Oxygen permeability index is defined as the negative $\log$ of the Darcy coefficient of permeability, with values above 10.0 indicating low permeability concrete while values less than 8.0 indicate high permeability (Alexander, et al., 2008). Figure 3 shows the measured oxygen permeability results after 28 days.

IPC was more permeable than PC-based concrete, with IPNZ concrete having considerably higher permeability (i.e., lower oxygen permeability index). Concrete mixes IPAS and IPSA were only slightly more permeable than PC concrete when thermally cured but ambient cured concrete had significantly higher permeability, which was consistent with the higher porosity found for these concretes. 
Carbonation of concrete is generally considered to be diffusion-controlled and higher oxygen permeability would indicate more rapid carbonation rates through concrete. The absence of calcium hydroxide in IPC could also influence chemical reaction-controlled processes and exacerbate carbonation rates. Findings by Bernal indicated that alkali-activated slag concretes are more susceptible to carbonation than equivalent PC concrete (2011)

\subsubsection{Chloride resistance}

IPC has higher than normal $\mathrm{pH}$ and this raises concerns about the passivation of embedded steel reinforcement since pore water $\mathrm{pH}$ may exceed 14 and falls outside passivation limits, possibly leading to caustic corrosion. Miranda did however find that reinforcing steel exposed to the highly alkaline environment of IPC quickly reached conditions indicative of a stable, passive layer (2005). Corrosion protection provided by IPC in the longer-term is dependent on the material maintaining sufficient alkalinity and resisting penetration of harmful agents such as chloride ions from the environment. Figure 4 shows chloride profiles measured after 90 days bulk diffusion testing of IPC and PCbased concrete. After salt water exposure, concrete was profile ground at $2 \mathrm{~mm}$ increments and total chloride content analysed using a potentiometric titration.
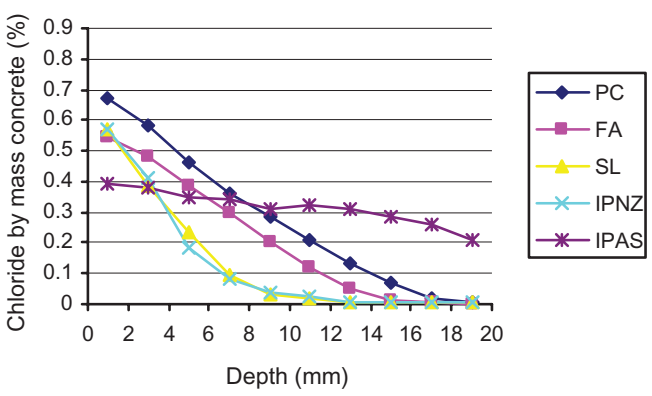

a) Cured at $21{ }^{\circ} \mathrm{C}$

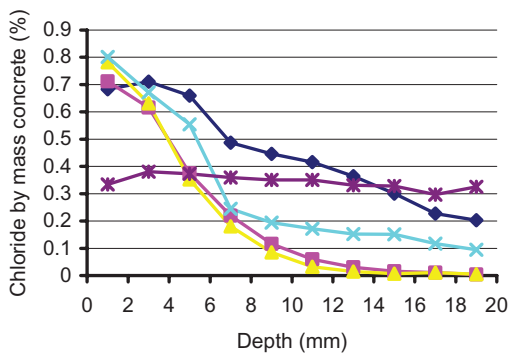

b) Cured at $60{ }^{\circ} \mathrm{C}$

Figure 4. Chloride profiles after 90 days bulk diffusion.
Table 5. Chloride resistance results after 90 days.

\begin{tabular}{llll}
\hline Concrete & Temp & $\begin{array}{l}\text { Nordtest } \\
\mathrm{D}_{\mathrm{c}}\end{array}$ & $\begin{array}{l}\text { Bulk diff. } \\
\mathrm{D}_{\mathrm{c}}\end{array}$ \\
\hline PC & $21^{\circ} \mathrm{C}$ & $6.6 \times 10^{-12}$ & $5.8 \times 10^{-12}$ \\
& $60^{\circ} \mathrm{C}$ & $1.1 \times 10^{-12}$ & $1.8 \times 10^{-11}$ \\
FA & $21^{\circ} \mathrm{C}$ & $1.9 \times 10^{-12}$ & $3.9 \times 10^{-12}$ \\
& $60^{\circ} \mathrm{C}$ & $1.3 \times 10^{-12}$ & $2.7 \times 10^{-12}$ \\
SL & $21^{\circ} \mathrm{C}$ & $1.7 \times 10^{-12}$ & $1.5 \times 10^{-12}$ \\
& $60^{\circ} \mathrm{C}$ & $1.8 \times 10^{-12}$ & $1.9 \times 10^{-12}$ \\
IPNZ & $21^{\circ} \mathrm{C}$ & $4.7 \times 10^{-12}$ & $1.3 \times 10^{-12}$ \\
& $60^{\circ} \mathrm{C}$ & $1.3 \times 10^{-11}$ & $5.3 \times 10^{-12}$ \\
IPAS & $21^{\circ} \mathrm{C}$ & $1.5 \times 10^{-12}$ & $7.9 \times 10^{-11}$ \\
& $60^{\circ} \mathrm{C}$ & $1.7 \times 10^{-12}$ & $2.1 \times 10^{-10}$ \\
IPSA & $21^{\circ} \mathrm{C}$ & $2.5 \times 10^{-11}$ & Not tested \\
& $60^{\circ} \mathrm{C}$ & $2.6 \times 10^{-11}$ & \\
\hline
\end{tabular}

The chloride resistance of FA and SL concrete was significantly better than PC concrete while some IPC mixes were poor. The chloride profile of IPAS was also extremely flat, which would indicate that little physical or chemical binding of chloride.

Results of chloride migration testing at 90 days are shown in Table 5 together with apparent diffusion coefficients measured after bulk diffusion testing. These techniques are quite different using chloride migration and diffusion respectively but measured diffusion coefficients usually have the same ranking if not equivalent values.

Given the high porosity of IPNZ, it was expected that this concrete would have the poorest chloride resistance. Contrary to expectations, ambient cured IPNZ had reasonable chloride resistance while IPAS and IPSA had poor chloride resistance regardless of the initial curing. Chemical binding of chloride ions could possibly be responsible for the unexpectedly good performance of IPNZ concrete. For other mixes, thermal curing was found to adversely affect chloride resistance, particularly IPAS.

Other research findings using ASTM C1202 found activated slag concrete to have very low chloride resistance when assessed using the total charge criterion of the test. This test method is dependent on the intrinsic conductivity of the concrete since all negatively charged ions act as charge carriers. IPC has significant differences in pore solution chemistry due to high concentrations of hydroxyl ions, which will influence the inherent conductivity of the material (Song and Jennings 1999).

\section{DISCUSSION}

Thermal curing had little adverse effect on the durability of PC-based concrete but slightly reduced the 
strength and stiffness of the material. Properties of IPNZ concrete were poorer when thermally cured and this material is best cured under ambient conditions. Other IPC mixes (IPAS and IPSA) had improved properties after thermal activation except for chloride resistance which was slightly poorer. This did not agree with research done by Mukhin who found that steam curing improved chloride resistance of concrete albeit to levels still far poorer than equivalent PC concrete (2007).

Porosity of IPC was found to be higher than PC-based concrete, which is only partly explained by the inherently higher porosity of IPC pastes. Increased porosity of IPC was also related to the lower workability of the material that produced more compaction voids. Concrete with a low yield shear stress (less than $500 \mathrm{~Pa}$ ) and moderate plastic viscosity (less than $100 \mathrm{~Pa}$.s) had approximately half the porosity of the equivalent paste. Less workable concrete with high yield shear stress and plastic viscosity had concrete porosity values of $70 \%$ of the equivalent paste.

Measuring the porosity of IPC provided a rough indication of oxygen permeability since only a moderate increase in porosity led to a significant change in permeability (shown in Figure 5). Measuring porosity of concrete provides only a bulk estimation of the quality of the microstructure. Chloride resistance of IPC was not consistently related to porosity and should be measured directly as is usually the case for PC-based concrete.

A reasonable correlation was found between diffusion coefficients measured using the Nordic chloride migration test and bulk diffusion testing (shown in Figure 6). While this was a limited study, analysis of results suggests that the chloride resistance of IPC can be estimated from accelerated techniques such as the Nordic chloride migration test. These rapid techniques must however be correlated with long-term diffusion test methods such as bulk diffusion when dealing with new materials such as IPC.

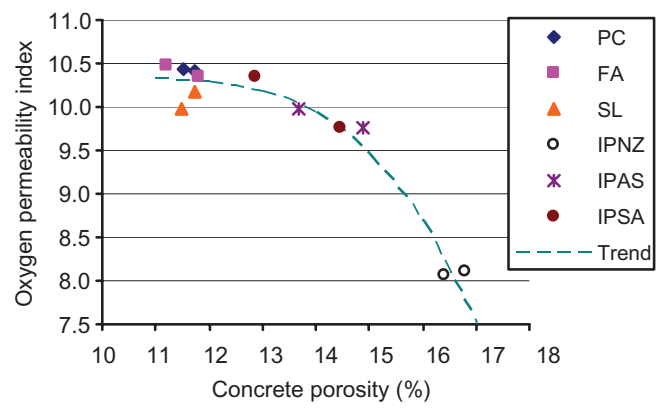

Figure 5. Oxygen permeability index versus concrete porosity.

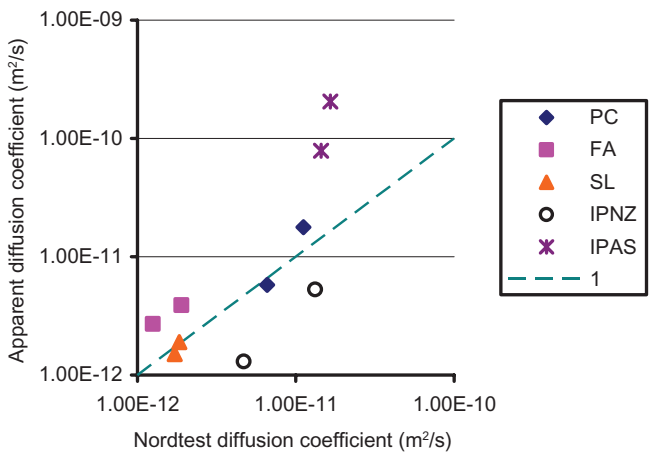

Figure 6. Comparing diffusion coefficients measured by bulk diffusion and migration.

Even if the chloride resistance of IPC is significantly improved, the corrosion performance of steel reinforcement embedded in IPC is still uncertain given the lack of buffering in the absence of calcium hydroxide in IPC but found in other PCbased concretes. There is also the concern that the permeable nature of IPC will allow alkali diffusion to occur that might reduce the $\mathrm{pH}$ of the pore water within the material and ultimately cause depaasivation of embedded steel reinforcement (Lloyd 2010).

\section{CONCLUSIONS}

The properties of PC-based concrete were not significantly affected by thermal curing and hardened properties were all within a predictable range. IPC was more sensitive to thermal curing both improving and adversely affecting the microstructure depending on the concrete type. The effect of these micro-structural changes was quite variable when analyzing permeation and diffusion characteristics of IPC. Careful characterization is therefore critical with these new materials to avoid over-estimating the performance of IPC.

Workability of IPC was relatively poor for some mixes due to relatively high plastic viscosity levels. This stickiness of some IPC mixes was shown to have contributed to increased porosity of the concrete due to insufficient compaction. Durability potential of IPC was found to be compromised by the high porosity, which increased permeation of the material. High strength IPC had poor chloride resistance that could be problematic in some applications, especially if coupled with a loss in alkalinity when exposed to water. Durability performance of IPC was variable and these concrete mixes need to be specially formulated and processed for the expected environmental and service conditions. 
High strength IPC mixes required thermal curing to stabilise the material and provide good structural and durability properties. The rapid setting of these materials would also limit their application to dedicated precast concrete applications where material can be batched, mixed, cast and finished within less than one hour. Further development of the technology will help broaden the application and improve the confidence in the durability properties of these materials.

\section{ACKNOWLEDGEMENTS}

This work was funded by the New Zealand Foundation for Research, Science and Technology as part of the Future Building Systems programme. The support of Fletcher Concrete and Infrastructure was also critical to the success of this research.

\section{REFERENCES}

Alexander, M.G., Mackechnie, J.R. \& Ballim, Y. 1999 Guide to durability indexes for achieving durability in concrete structures Research Monograph No. 2, University of Cape Town.

Alexander, M.G., Ballim, Y. \& Stanish, K, 2008. A framework for use of durability indexes in performancebased design and specifications for reinforced concrete structures, Materials and Structures, 41: 921-936.

American Society for Testing and Materials, 2002. Test method for static modulus of elasticity and Poisson's ratio for concrete in compression, ASTM C469. Philadelphia.

American Society for Testing and Materials, 2004. Standard test method for determining the apparent chloride diffusion coefficient of cementitious mixtures by bulk diffusion, ASTM C1556-04. Philadelphia.

Australian Standards, 1992. AS1012.13 - Determination of the drying shrinkage of concrete for samples prepared in the field or in the laboratory, Canberra.

Bernal, S.A., de Gutierrez, R.M., Pedraza, A.L., Provis, J.L., Rodriquez, E.D. \& Delvasto, S. 2011. Effect of binder content on the performance of alkali-activated slag concretes. Cement and Concrete Research, 41: 1-8.
Criado, M., Palomo, M., Fernandez-Jimenez, A. \& Banfill, P.F.G. 2009. Alkali activated fly ash: effect of admixtures on paste rheology. Rheologica ACTA, 48: $447-455$

Duxson, P., Fernandez-Jimenez, A., Provi,s J.L., Lukey, G.C., Palomo, A. \& van Deventer, J.S.J. 2007. Geopolymer technology: the current state of the art, Journal of Material Science, 42: 2917-2933.

Kovalchuk, G., Fernandez-Jimenez, A. \& Palomo, A. 2007. Alkali-activated fly ash: effect of thermal curing conditions on mechanical and microstructural development-part II. Fuel, 86: 315-322.

Lloyd, R.R., Provis, J.L., Smeaton, K.J. \& van Deventer J.S.J. 2009. Spatial distribution of pores in fly ashbased inorganic polymer gels visualised by Wood's metal intrusion. Microporous and Mesoporous Materials, 126: 32-39.

Lloyd, R.R., Provis, J.L. \& van Deventer, J.S.J. 2010. Pore solution composition and alkali diffusion in inorganic polymer cement, Cement and Concrete Research, 40: 1386-1392.

Miranda, J.M., Fernandez-Jimenez, A., Gonzalez, J.A. \& Palomo, A. 2005. Corrosion resistance in activated fly ash mortars, Cement and Concrete Research, 35: $1210-1217$.

Mukhin, V., Khatri, R. \& Dumitru, I. 2007. Some limitations of geopolymer concrete 23rd Biennial Conference of the Concrete Institute of Australia Adelaide.

New Zealand Standards, 1986. NZS 3112 Part 1 and 2: Methods of testing for concrete, Wellington.

Nordtest, 1999. Chloride migration coefficient from nonsteady-state migration experiments, Espoo, Finland.

Phair, J.W. 2006. Green chemistry for sustainable cement production and use. Tutorial review. Green Chemistry, 8: 763-780.

Roy, D.M. \& Silsbee, M.R. 1992.. Alkali activated materials. An overview. Mater. Res. Soc. Symp. Proc. 245: 153-164.

Song, S. \& Jennings, H.M. 1999. Pore solution chemistry of alkali-activated ground granulated blast-furnace slag. Cement and Concrete Research, 29: 159-170.

Wangpo, J., Kiattikomol, K., Jaturapitakkul, C. \& Chindaprasirt, P. 2010. Compressive strength, modulus of elasticity and water permeability of inorganic polymer concrete. Materials and Design, 31: 4748-4754. 